\title{
Sobre a produtividade e a semântica do prefixo des- no português brasileiro atual ${ }^{*}$
}

\section{On the productivity and semantics of the prefix des- in current Brazilian Portuguese}

\author{
Camila De Bona \\ (Universidade Federal do Rio Grande do Sul, Porto Alegre, \\ Rio Grande do Sul, Brasil) \\ Pablo Nunes Ribeiro \\ (Universidade Federal de Santa Maria, Santa Maria, \\ Rio Grande do Sul, Brasil)
}

\section{RESUMO:}

O estatuto semântico do prefixo des- no português tem sido um tópico bastante discutido na literatura recente. Neste trabalho, objetiva-se retomar os dados de Bona (2014) para verificar a hipótese de que o prefixo des- tenha passado a denotar apenas a reversão de uma trajetória de mudança (aplicando-se produtivamente a verbos de mudança ou nomes deverbais), não mais se configurando como um prefixo de negação de estado. Para fins de análise, como referencial teórico, elegemos o modelo de Lieber (2004), o qual apresenta um conjunto de traços semânticos para a descrição de afixos, tais como [-Loc], para negações, e [+IELTS], para trajetórias. Concomitante a isso, uma pesquisa diacrônica sobre a datação de entrada desses itens lexicais no português foi feita, além de

\footnotetext{
* Este trabalho é fruto das pesquisas de Mestrado, de Camila De Bona, e de Doutorado, de Pablo Nunes Ribeiro, sob a orientação, respectivamente, de Sabrina Pereira de Abreu e Sergio de Moura Menuzzi, ambas financiadas pelo CNPq. Agradecemos aos nossos então orientadores, pelas preciosas contribuições, e aos pareceristas anônimos, pelas sugestões ao manuscrito. Os erros remanescentes são de nossa responsabilidade.
} 
uma comparação com itens neológicos, para avaliar a produtividade, no português brasileiro atual, do prefixo des-.

Palavras-chave: Prefixo des-. Semântica lexical. Reversão. Negação.

\section{ABSTRACT}

The semantic status of the Portuguese prefix des- has been a much discussed topic in recent literature. In this paper, we revisit the data from Bona (2014) with the objective of verifying the hypothesis that the prefix des- has come to denote only the reversal of a trajectory of change (productively applying to verbs of change or to deverbal nouns), no longer being configured as a negation of state prefix. For analysis purposes, as a theoretical framework, we chose the semantic model from Lieber (2004), which presents a set of semantic features to the description of affixes, such as [-Loc] for denials and [+ IELTS] for paths. Furthermore, a diachronic research on the date of entry of these lexical items in Portuguese was done, as well as a comparison with neological items to evaluate the productivity of prefix des- in current Brazilian Portuguese.

Keywords: Prefix des-. Lexical semantics. Reversion. Negation.

\section{Introdução}

Este trabalho, o qual se insere na área dos estudos de Semântica Lexical, mais especificamente nos estudos sobre o significado de morfemas derivacionais prefixais, tem como objetivo estudar os aspectos semânticos do prefixo des- no português brasileiro (doravante $\mathrm{PB}$ ).

Segundo Lieber (2004), uma pergunta há muito presente nos estudos morfológicos e que se faz relevante ainda procurar responder é a seguinte: por que determinados afixos são polissêmicos e, ao mesmo tempo, temos uma diversidade de afixos para lidar com uma mesma função e significado? O prefixo des- tem sido descrito na literatura linguística como um prefixo polissêmico apresenta tanto um significado de negação quanto de reversão nos itens lexicais a que se adjunge. Com este trabalho, analisamos os vocábulos prefixados por des- no português, através de um dos traços semânticos propostos por Lieber (2004). Nosso objetivo é buscar indícios de que o significado de negação associado a esse prefixo não é mais produtivo no PB atual: novas formações de palavras com o prefixo des- tendem a atualizar sua semântica de reversão. 
A organização deste artigo se dá da seguinte maneira: na seção 1 , revisitamos a literatura linguística do $\mathrm{PB}$ no que tange às descrições feitas para o prefixo des-. A seção 2 apresenta nosso referencial teórico, qual seja o modelo de Lieber (2004). A seção 3 apresenta nossos procedimentos metodológicos, seguida pela análise de dados. As conclusões obtidas serão relatadas juntamente com nossas considerações finais.

\section{Revisitando a literatura: prefixo des-}

Na literatura linguística do português brasileiro, já temos muitas descrições e discussões acerca do prefixo des-, principalmente no que tange à sua semântica em estruturas verbais e adjetivais. Com isso em mente, tencionamos revisitar as principais ideias já propostas por estudiosos que se debruçaram sobre o tema, delineando a importância de suas contribuições para o desenvolvimento deste trabalho.

Primeiramente, abordaremos os argumentos de Silva e Mioto (2009), os quais defendem a existência de uma seleção rígida feita pelos prefixos, à semelhança do que acontece com os sufixos. Após, elucidaremos as contribuições de Medeiros (2010) e Ribeiro (2014) relativamente ao prefixo des-.

\subsection{Prefixos: seleção categorial rígida?}

Em artigo de 2009 intitulado Considerações sobre a Prefixação, Silva e Mioto defendem a hipótese de que os prefixos, assim como os sufixos, também selecionam rigidamente a base com a qual se combinam. Tendo em vista que os sufixos determinam a classe da palavra que formam, seu estudo nunca negligenciou a classe da palavra que the serve como base; consequentemente, gerou-se um consenso de que os sufixos selecionam a sua base. No entanto, isso nunca ocorreu em relação aos prefixos: mesmo sendo considerados pela tradição gramatical como formadores de palavras derivadas, na maioria das vezes temse sua organização em ordem alfabética dentro de dois grandes grupos - o latino e o grego (cf.: Silva; Mioto 2009:1-2).

Contra essa tradição, Silva; Mioto (2009) argumentam que também os prefixos selecionam a base com a qual irão se combinar, sendo que essa seleção envolve tanto a sua categoria quanto certas características semânticas presentes nela. Uma das principais motivações para essa proposta seria a necessidade de evitar a ambiguidade estrutural em palavras como desmobilização, que poderia ter três derivações possíveis, assumindo-se que o prefixo não seleciona rigidamente a base: 
(1) Possibilidades de formação para desmobilização (Silva; Mioto 2009:15-16)

a.

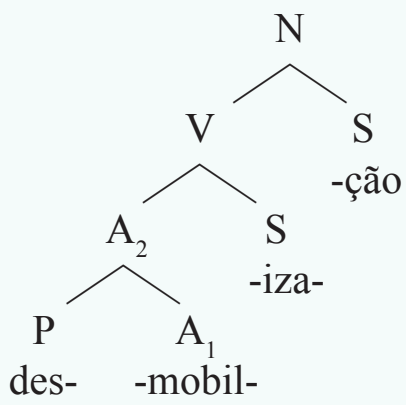

b.

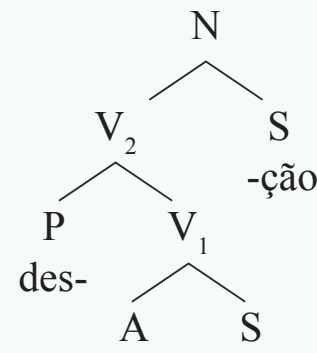
-mobil- -iza-

c.<smiles>N#C[Ge]=C1CCCCC1</smiles>

Segundo Silva e Mioto (2009), a hipótese da seleção rígida não tolera essa variedade de opções para a formação da supracitada palavra. Considerando que des- é produtivo com verbos (desfazer, desconectar, desinfetar, destelhar, desconsiderar, etc.) e que, na palavra desmobilização, há um um sentido de reversão, os autores assumem que a derivação correta é (b). Contudo, o fato de des- também ocorrer com adjetivos no português (desnecessário, desleal, desumano, deselegante, desigual, etc.) poderia sugerir que a derivação em (a) também fosse possível. Para manter o pressuposto da seleção rígida e lidar com esse problema, Silva e Mioto postulam um prefixo homônimo, que se liga a bases adjetivais. Além de uma base de classe diferente, esse prefixo também, segundo eles, apresenta um significado diverso: 
Se se combina com um verbo, seu sentido é de reversão de um processo; se se combina com adjetivo, seu sentido é de um tipo de negação. De fato, desleal significa algo como 'sem lealdade', mas desfazer não significa 'sem (não) fazer'. Podemos, portanto, hipotetizar que des- exemplifica um caso de homonímia de prefixos e que, por isso, deve haver (pelo menos) duas entradas para ele no dicionário de morfemas do português. Cada uma das entradas terá suas propriedades de seleção: des-1, que significa reversão, seleciona verbos; des2, que significa negação, seleciona adjetivos. (Silva; Mioto 2009:17)

Acerca das propriedades semânticas da base, observamos que muitos prefixos selecionam rigidamente alguns traços da base com a qual se combinam. Em português, essa ideia encontra respaldo na distribuição do prefixo verbal des-. Os autores o consideram como uma espécie de marcador aspectual que expressa reversão. De imediato, pode-se dizer que ele não pode se combinar com verbos que não denotam processos ou que denotam processos irreversíveis, como *desmorrer, *deschegar, *deslavar, *desdesejar, *desnadar, *dessonhar. Por outro lado, ele se combina perfeitamente com verbos de processo, como desfazer, desmontar, desnivelar, desligar, desconstruir, desarrumar. As impossibilidades de combinação do prefixo des- com determinadas bases decorrem da incompatibilidade semântica entre o prefixo e o aspecto da eventualidade denotada pela base.

Relativamente às considerações semânticas feitas pelos autores, de que des- veicula o significado reversativo quando adjungido a verbos e o significado negativo quando se liga a adjetivos, uma questão surge: como poderíamos analisar o caso dos verbos gostar, crer, amar, os quais licenciam a formação com des-, mesmo não denotando processos de mudança e não apresentando, quando prefixados por des-, o sentido de reversão mas, antes, o de negação? A ideia que aqui defendemos é a de que, com verbos de estado e alguns verbos de ação, o prefixo des- dispara a mesma semântica que com adjetivos, qual seja a de negação. Portanto, as noções de reversão e negação não podem ser automaticamente associadas às categorias de verbos e adjetivos, respectivamente, tendo em vista a necessidade primeira de averiguação da semântica da base. Levando em conta esse argumento, a postulação de dois des- homófonos perde credibilidade, já que a semântica do prefixo não é necessariamente diferente quando a categoria gramatical é diversa.

No que diz respeito à postulação de uma seleção categorial rígida por parte dos prefixos, verificaremos a plausibilidade dos argumentos dos autores na análise de nossos dados. Desde já, podemos adiantar que a seleção categorial de des- com verbos e adjetivos, como defendida pelos autores, não é categórica. 


\subsection{A análise de Medeiros (2010)}

Ao investigar a natureza do prefixo des- usando o arcabouço teórico da Morfologia Distribuída (Halle; Marantz 1993, Marantz 1997), Medeiros (2010) defende que o prefixo des- não faz seleção categorial (contrariamente a Silva; Mioto 2009), mas sim uma seleção de natureza semântica, modificando somente verbos cujos significados envolvam um elemento com interpretação estativa. Os verbos que aceitam a prefixação com des-, segundo o autor, pressupõem um estado, o qual é normalmente consequente ou alvo do processo que tal verbo denota: "Refiro-me ao estado que seu complemento, quando o verbo é transitivo, atinge sempre que o referido processo culmina" (Medeiros 2010:97). Nesse contexto, o prefixo em questão nega ou inverte tal estado, não o processo associado. Medeiros aponta como reforço a essa ideia o fato de que os típicos verbos que denotam atividade normalmente não o aceitam: *descorrer, *destrabalhar, *desdançar, *despular, *desgritar, *desfalar. $\mathrm{O}$ argumento principal é que esses verbos não denotam um processo de mudança de estado (e, portanto, não selecionam um argumento afetado), por isso não servem de base para uma derivação que envolva tal prefixo.

Ao assumir a ideia de que o prefixo des- nega um estado (interno ao verbo), Medeiros propõe que o prefixo só poderá se combinar com (e modificar) um nó cujo tipo semântico for um estado, independentemente de sua classe morfológica ou categoria gramatical:

$$
[[\mathrm{NEG}]]=\lambda \mathrm{f}<\mathrm{s}, \mathrm{t}>. \lambda \mathrm{s} .[\neg \mathrm{f}(\mathrm{s})]
$$

(Medeiros 2010:110)

Com essa representação, o autor estabelece um único sentido para o prefixo des-, o qual opera transcategorialmente, atualizando a ideia de negação ou inversão de um estado. Abaixo, temos exemplificado (de acordo com o modelo da Morfologia Distribuída) o nó em que o prefixo é anexado na estrutura: des- não pode tomar o vP inteiro, tendo em vista que este inclui um evento categoria semântica incompatível com a denotação de NEG proposta. O prefixo combina-se, então, com a raiz $(\sqrt{ } \mathrm{P})$, tendo como escopo o participante do evento que sofre a mudança de estado:

(2) Anexação do prefixo des- a verbos (Medeiros 2010:110)

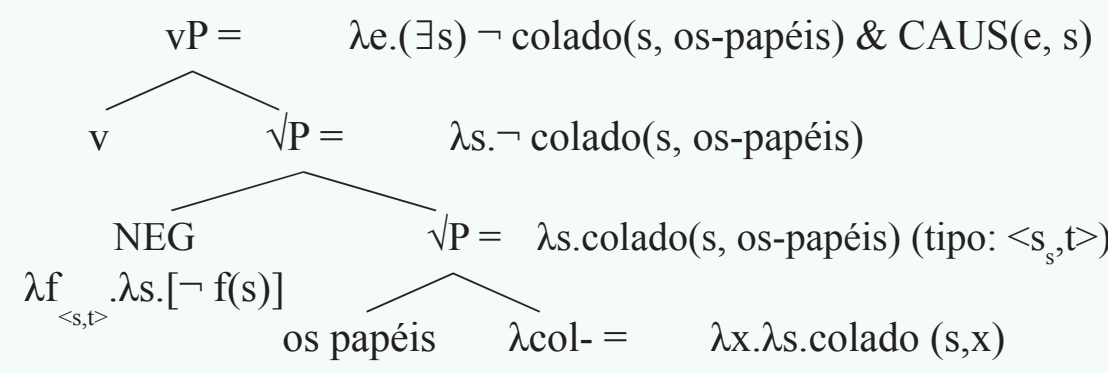


Como podemos observar em (2), a função NEG (denotada pelo prefixo des-) toma como argumento o estado denotado pela raiz $\sqrt{ }$ col- (ou seja, "colado") e retorna a negação desse estado. No artigo, o autor defende que uma abordagem baseada numa seleção por tipos semânticos pode ser mais interessante do que uma abordagem baseada na seleção categorial, e que uma abordagem sintática, em que o prefixo des- modifica uma predicação interna ao verbo de base, nos levaria a generalizações importantes sobre os dados.

No que tange aos adjetivos, Medeiros aponta que, por eles definirem funções que associam uma entidade a uma função que liga um estado a um valor de verdade, aceitam a prefixação com des-. Além dos adjetivos, alguns nomes de estado, mais especificamente os de estados psicológicos (afeto, amor, ânimo, temor, etc.), também aceitam a prefixação, pois, de acordo com Medeiros, seu tipo semântico é compatível com o tipo selecionado pelo nó NEG:

(3) Anexação do prefixo des- a nomes (Medeiros 2010:116)

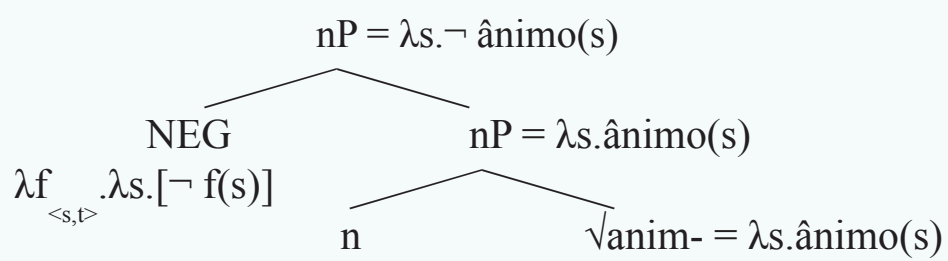

Se a definição semântica do nó NEG envolve uma função de estado, como propõe o pesquisador, esperamos não encontrar o prefixo des- em nomes de eventos, como dança, trabalho, pulo, nem em nomes de entidades no mundo, como cachorro, gato, pedra. Isso se deve ao fato de nomes como esses denotarem funções incompatíveis com as propriedades de seleção semântica associadas ao prefixo.

Como conclusão, diferentemente de Silva e Mioto (2009), o autor aponta que o prefixo des- seleciona estados e não se prende a categorias morfossintáticas, podendo ocorrer em verbos, nomes e adjetivos. Ao conhecer as denotações semânticas dessas classes de palavras e as estruturas de evento associadas aos verbos, compreendemos a distribuição do prefixo des-, chegando à sua denotação: "uma denotação única, que evita a multiplicação de entradas lexicais para o prefixo" (Medeiros 2010:118).

De fato, a proposta de Medeiros apresenta uma alternativa de análise para o problema da proliferação de homônimos no léxico (des-1 e des-2) presente em Silva e Mioto (2009), que são analisados pelos autores como se não tivessem relação entre si. No entanto, sua descrição semântica do prefixo como "negação ou inversão de um estado que pode decorrer de um processo" é contestada por Ribeiro (2014), como veremos na próxima subseção. 


\subsection{A análise de Ribeiro (2014)}

Ribeiro (2014) desenvolve uma proposta para tratar da semântica do prefixo des- sob a luz da Semântica Conceitual, teoria proposta e formalmente desenvolvida por Ray Jackendoff em Semantics and Cognition (1983) e em Semantic Structures (1990). Com o intuito de recuperar o poder explicativo da hipótese locacional de Jackendoff, Ribeiro apresenta uma proposta para o tratamento de eventos com base na extensão metafórica do predicado primitivo GO. O autor defende que sua análise, baseada nas funções primitivas GO e FROM, apresenta um poder explicativo maior do que o das propostas de Silva e Mioto (2009) e de Medeiros (2010) no que diz respeito aos aspectos semânticos, possibilitando uma análise locacional da semântica do prefixo des-.

A proposta defendida por Ribeiro segue a linha da de Silva e Mioto (2009), com a ideia de que os verbos com o prefixo des-denotam a reversão de um processo de mudança, e não a negação de um estado resultante, como defende Medeiros (2010). O pesquisador defende, assim como Medeiros (2010), a ideia de que verbos com o prefixo des-, de fato, não pressupõem o evento correspondente ao verbo sem o prefixo, mas, diferentemente, assume que esses verbos denotam o processo de mudança inverso ao que a sua contraparte sem o prefixo denota (Ribeiro 2014:133):

\footnotetext{
Mais especificamente, acredito que a contribuição semântica do prefixo des- para a estrutura léxico-conceitual de um evento seja a inversão da direção da trajetória de mudança, ou seja, a substituição do predicado locacional TO pelo predicado FROM.
}

Para mostrar a pertinência de sua proposta frente às outras, Ribeiro (2014:133) analisa o caso dos verbos descongelar e desorganizar. De acordo com sua teoria, a mudança de estado envolvida em verbos como congelar e organizar deve ser representada por meio dos predicados $\mathrm{GO}$ e $\mathrm{TO}$, e eventos denotados por esses verbos teriam representações como em (4b) e (6b), respectivamente. O prefixo des-, então, modificaria essas representações revertendo a direção da mudança de estado com a introdução do predicado FROM, como vemos em (5b) e (7b) abaixo.

(4) a. O lago congelou.

$$
\begin{array}{r}
\text { b. }\left[_ { \text { Event } } \mathrm { GO } _ { \text { Circ } } \left(\left[_{\text {Thing }} \mathrm{LAGO}_{i}\right],\left[\left[_ { \text { Path } } \mathrm { TO } _ { \text { Circ } } \left[{ } _ { \text { State } } \mathrm { BE } _ { \text { Ident } } \left(\left[_{\text {Thing }} \mathrm{X}_{i}\right],\right.\right.\right.\right.\right.\right. \\
\left.\left.\left.\left[\mathrm{CPT}_{\text {Place }} \mathrm{AT}_{\text {Ident }}\left(\left[\left[_{\text {Property }} \text { CONGELADO }\right]\right)\right]\right)\right]\right)\right]
\end{array}
$$

(5) a . O lago descongelou.

$$
\begin{aligned}
& \text { b. }\left[_ { \text { Event } } \mathrm { GO } _ { \text { Circ } } \left(\left[_{\text {Thing }} \mathrm{LAGO}_{i}\right],\left[_ { \text { Path } } \mathrm { FROM } _ { \text { Circ } } \left[_ { \text { State } } \mathrm { BE } _ { \text { Ident } } \left(\left[_{\text {Thing }} \mathrm{X}_{i}\right],\right.\right.\right.\right.\right. \\
& \left.\left.\left.\left[\mathrm{PT}_{\text {Place }} \mathrm{AT}_{\text {Ident }}\left(\left[\left[_{\text {Property }} \text { CONGELADO }\right]\right)\right]\right)\right]\right)\right]
\end{aligned}
$$


(6) a. O time se organizou.

a. O time se desorganizou.

$$
\begin{aligned}
& \text { b. }\left[_ { \text { Event } } \mathrm { GO } _ { \text { Circ } } \left(\left[_{\text {Thing }} \mathrm{TIME}_{i}\right],\left[_ { \text { Path } } \mathrm { TO } _ { \text { Circ } } \left[_ { \text { State } } \mathrm { BE } _ { \text { Ident } } \left(\left[_{\text {Thing }} \mathrm{X}_{i}\right]\right.\right.\right. \text {, }\right.\right.
\end{aligned}
$$

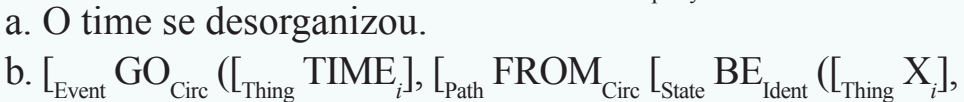

$$
\begin{aligned}
& \left.\left.\left.\left[_{\text {Place }} \mathrm{AT}_{\text {Ident }}\left(\left[\left[_{\text {Property }} \text { ORGANIZADO }\right]\right)\right]\right)\right]\right)\right]
\end{aligned}
$$

$$
\left.\left.\left.\left.{ }_{\text {Place }} \mathrm{AT}_{\text {Ident }}\left(\left[\left[_{\text {Property }} \text { ORGANIZADO }\right]\right)\right]\right)\right]\right)\right]
$$

(Ribeiro 2014:133)

Ademais, o autor argumenta que a estrutura léxico-conceitual de eventos denotados por verbos como descascar e desossar também pode ser representada de forma adequada por predicados locacionais, já que esses verbos não denotam uma mudança de estado simples, mas antes a retirada de uma parte do todo representado pela entidade denotada pelo objeto direto. Essa semântica, segundo o autor, pode ser obtida também por meio dos predicados GO e FROM, o que possibilitaria uma análise mais uniforme da formação de verbos com o prefixo des-. Além disso, essa análise ofereceria uma explicação natural para a impossibilidade de formação de verbos como *desdançar, *despular ou *descorrer, tendo em vista que verbos de atividade não implicam nenhum tipo de deslocamento ao longo de uma trajetória, sendo esta espacial ou metafórica, já que não são verbos de mudança. Considerando que o prefixo des- modifica uma trajetória por meio da introdução do predicado FROM, "a estrutura léxico-conceitual de eventos como correr ou pular não é compatível com a semântica do prefixo e, portanto, não serve como base para a derivação" (Ribeiro 2014:134).

Ribeiro (2014), ao seguir a linha de argumentação de Silva e Mioto (2009) e não a de Medeiros (2010), defende que sua proposta consegue determinar com maior precisão a relação entre a forma prefixada e a forma não prefixada do verbo, além de oferecer uma explicação natural para a operação morfológica envolvida nesses casos. No entanto, o autor deixa para pesquisas futuras a investigação sobre a possível extensão de sua proposta para a prefixação com bases adjetivais (p. ex., desleal, desonesto), com o intuito de eliminar a necessidade do postulado de um caso de homonímia para o prefixo des-, o qual parece ser, de fato, o ponto nevrálgico da análise apresentada por Silva e Mioto (2009).

No presente trabalho, seguiremos a linha de análise de Ribeiro (2014), assumindo que o prefixo des- denota produtivamente uma reversão na trajetória de mudança presente na semântica da base com a qual se combina, e procuramos indícios de que o processo de formação de palavras que resulta em um significado de simples negação para o prefixo des- não é mais produtivo no $\mathrm{PB}$. 


\section{O estudo de Liber (2004)}

$\mathrm{Na}$ parte introdutória de sua obra, Rochelle Lieber (2004) aponta que seu livro trata da semântica da formação de palavras. Mais especificamente, trata do significado dos morfemas e de como eles se combinam para formar o significado de palavras complexas, incluindo palavras derivadas, compostos e palavras formadas por conversão. A autora esclarece que, até então, não existia nenhum estudo tão abrangente na tradição da morfologia gerativa que tratasse da semântica da formação de palavras quanto o estudo que ela se propôs a encetar. Uma das razões para isso, segundo ela, seria, provavelmente, o início tardio da morfologia na história da gramática gerativa, tendo em vista que sua consideração como legítimo campo de estudo se deu apenas na metade dos anos 1970 e, ainda assim, seus estudos se concentraram mais nas questões estruturais e fonológicas, em detrimento das questões de ordem semântica. No entanto, uma razão ainda mais importante, argumenta a pesquisadora, seria a de que, até então, uma forma sistemática de tratar da semântica lexical da formação de palavras (opostamente à semântica das palavras) ainda nos falta.

A pesquisadora defende em sua obra a premente necessidade de descrever e comparar os efeitos semânticos dos processos de formação de palavras em detalhe e profundidade para poder resolver a questão do tratamento dos morfemas: estes devem ser tratados como signos saussureanos, em um pareamento entre som e significado? Como falamos de significados que podem estar em correspondência com unidades estruturais? Lieber argumenta que essas perguntas não podem ser respondidas através da análise da arquitetura da teoria morfológica, pelo menos não até se encontrar uma forma de descrever os efeitos semânticos dos processos de formação de palavras em algum detalhe e profundidade. Para a autora, não seremos capazes de falar sobre a correspondência entre forma e significado até que possamos dizer de forma efetiva o que palavras complexas de fato significam - qual o significado ou significados que o prefixo des-, por exemplo, apresenta? Um ou muitos significados? E, se muitos, são eles relacionados?

A autora aponta que não temos ainda o aparato teórico necessário para encetar tais discussões. Para falar da semântica da formação de palavras, precisamos de uma estrutura descritiva da semântica lexical que apresente muitas propriedades distintivas. Primeiro, segundo Lieber, precisa ser decomposicional: deve envolver um número relativamente pequeno de primitivos ou átomos semânticos, e estes devem ter uma delimitação fina capaz de nos permitir falar dos significados de palavras complexas. Além disso, essa estrutura descritiva deve permitir que nos concentremos nas propriedades semânticas lexicais ao invés das propriedades semânticas que se manifestam apenas em níveis mais altos da estrutura sintática (assim como sintagmas, sentenças, proposições, etc.). Também deve ser completamente transcategorial, permitindo-nos discutir em 
igual profundidade as características semânticas de nomes, verbos, adjetivos, etc. Finalmente, tendo em mente que a formação de palavras frequentemente cria novos lexemas, essa teoria deve permitir que falemos dos significados de palavras complexas da mesma forma que costumamos falar do significado de lexemas primitivos.

Além disso, Lieber (2004:9-10) concebe as representações semânticas dos itens lexicais como sendo compostas de duas partes: o esqueleto gramáticosemântico e o corpo pragmático-semântico. O primeiro forma a base do que sabemos sobre morfemas e palavras. É o que nos permite estender o léxico através de vários processos de formação de palavras. O corpo agrega mais informações e detalhes a essa base; pode agregar mais ou menos dependendo do item lexical em questão e dependendo, também, da representação lexical desse item no léxico mental de cada pessoa em particular. Os corpos podem mudar com o tempo de vida de um item lexical - ganhar ou perder peso, por assim dizer. Os esqueletos, por outro lado, são menos suscetíveis a tais mudanças.

Lieber afirma que a semântica da formação de palavras envolve a criação de uma única unidade referencial composta por dois esqueletos semânticos distintos que são postos numa relação de justaposição ou de subordinação relativamente ao outro. A afixação derivacional mais especificamente envolve, então, a adição de um esqueleto semântico subordinado ao esqueleto semântico de uma base; em outras palavras, a representação semântica de um afixo derivacional terá um pouco do esqueleto semântico que subordina uma base lexical. As palavras derivadas, com o tempo, desenvolvem corpos substanciais e distintos em função de sua lexicalização. A lexicalização atua individualmente, item por item, permitindo a existência de uma variada gama de significados em itens lexicais muitas vezes originados pelo mesmo processo.

Na próxima subseção, faremos uma breve explanação de cada um dos traços semânticos propostos pela pesquisadora e daremos especial foco e detalhamento ao traço [Location], o qual será de nosso interesse para a descrição do prefixo de negação des-.

\subsection{Os traços semânticos propostos por Lieber}

Ao longo de sua obra, Lieber propõe seis traços semânticos, quais sejam, em inglês: [Material], [Dynamic], [IEPS], [Location], [B] e [CI]. Esses traços, binários em valor (isto é, positivo ou negativo), permitem distinguir as principais categorias ontológicas dos lexemas, assim como conceitos básicos de tempo, espaço e quantidade. Dependendo do item lexical, os traços acima podem estar presentes ou ausentes no esqueleto semântico, tendo em vista a relevância de seu conteúdo para a caracterização do item lexical em questão.

$\mathrm{O}$ traço [+/- material] define a categoria conceitual de substâncias, coisas ou essências e é correspondente nocional da categoria sintática Nome. O valor 
positivo denota a presença de materialidade, caracterizando nomes concretos, como cadeira, mesa, homem. Analogamente, o valor negativo denota ausência de materialidade, definindo nomes abstratos, como amor, tempo, paciência.

[+/- dynamic] assinala um significado situacional ou eventivo e, por si só, indica a categoria conceitual de Situações. O valor positivo corresponde a um evento ou processo (como beijar, comer), e o negativo, a um estado (como saber, ter).

Já o traço [+/- IEPS], sigla para Inferable Eventual Position or State (Posição em um Evento ou Estado Inferível), permite capturar algumas das principais classes aspectuais dos verbos. Se esse traço for positivo em determinado item lexical, teremos uma sequência tal de lugares/estados em que haja, em algum ponto entre o lugar/estado inicial e final, alguma progressão em direção ao estado/lugar final; evaporar, cair, esquecer são exemplos de palavras com o traço [+IEPS]. Se esse traço for negativo, não podemos fazer nenhuma inferência sobre a progressão de lugares/estados; exemplos são as palavras caminhar, correr, flutuar. A adição desse traço na caracterização dos itens lexicais sinaliza a adição do componente de significado trajetória.

Relativamente à semântica de quantidade, Lieber propõe dois traços, quais sejam [+/- B] e [+/- CI]. O primeiro significa bounded (em português, restrito) e assinala a relevância de fronteiras espaciais ou temporais intrínsecas em uma situação ou substância/coisa/essência. Se esse traço estiver ausente, o item pode ser ontologicamente limitado ou não, mas suas fronteiras devem ser conceitualmente e/ou linguisticamente irrelevantes. Se o item lexical tiver o traço [B] marcado positivamente, este é limitado espacial ou temporalmente, como pessoa, gato, mesa; e se for [-B], não apresenta limites intrínsecos de tempo ou espaço, como mobília, água.

Já [CI] significa Composto de Indivíduos (Composed of Individuals, no original) e assinala a relevância de unidades temporais ou espaciais implicadas no significado de um item lexical. Se um item for [+CI], ele é concebido como composto de unidades internas similares passíveis de separação, como comitê, rebanho, gado; diferentemente, se for [-CI], denota um item que é homogêneo temporal ou espacialmente ou, ainda, internamente indiferenciado, tais como pessoa, água.

O traço semântico de que trataremos em detalhe neste trabalho será [Loc], ou seja, localização (ou location, no original). Esse traço é atribuído a itens lexicais para os quais posição ou lugar no tempo/espaço é relevante. Consequentemente, em itens que não apresentarem esse traço, a noção de posição ou espaço é irrelevante. Itens lexicais que apresentarem o traço [+Loc] pertencem a alguma posição ou espaço; já os itens que apresentarem o traço negativo serão aqueles para os quais a falta explícita de posição ou lugar é assegurada. Com efeito, Lieber assinala, [-Loc] sinaliza a noção de falta ou 
privação, principalmente na caracterização de determinados verbos, nomes e adjetivos que apresentam negação através de afixos derivacionais.

Para melhor entendermos esse traço semântico, que será importante para o desenvolvimento deste trabalho, passemos à subseção seguinte.

\subsection{O traço [Loc]}

Com o objetivo de ampliar seu sistema de representação da semântica lexical, Lieber aborda em detalhe o traço [Loc] e mostra como ele pode ser utilizado na análise de muitos afixos, inclusive prefixos negativos e preposicionais. Com essa abordagem, além de aprofundar o conhecimento acerca do esqueleto e do corpo semântico de seu sistema, a pesquisadora explora duas das questões tão caras a ela expostas na introdução de sua obra, quais sejam: por que múltiplos afixos frequentemente ocupam o mesmo espaço semântico, e por que esses afixos, ao mesmo tempo, apresentam polissemia.

O traço [Loc], assim como todos os traços do sistema proposto por Lieber, deve ter uma utilidade ampla e variada entre as categorias lexicais, tanto no léxico comum quanto na morfologia derivacional. A presença desse traço no esqueleto semântico assegura a relevância de posição no espaço na semântica de um determinado item lexical; o traço em questão pode ser positivo ou negativo: o valor positivo assegura a posição ou o lugar, e o valor negativo nega a posição no espaço ou no tempo, assinalando a noção de falta ou privação.

Em termos de itens lexicais primitivos, começamos com o exemplo da presença do traço [Loc] em verbos estativos. Levin (1993) os caracteriza como 'verbos de existência', os quais também podem ser chamados de verbos de localização; são eles: ficar, ter, permanecer, existir, habitar, etc. Após atribuirmos o traço [+Loc] a esses verbos, tendo em vista a essência binária de traços no sistema, tem-se a premência de caracterização de verbos estativos de não existência ou talvez de privação de localização, ou seja, [-Loc]. Enquanto essa parece ser uma consequência estranha desse sistema de representação por traços, não é uma má consequência, defende Lieber, já que temos alguns candidatos plausíveis de verbos passíveis de estar nessa categoria, tais como faltar, carecer, perder, sumir, extraviar, etc. O significado privativo do verbo faltar, por exemplo, é bastante claro: faltar é "não ter". De forma similar, o adjetivo ausente tem um transparente significado privativo: estar ausente é não estar em algum lugar. Perder, sumir e extraviar também denotam uma privação de localização, ou, ainda, uma localização não atestada ou conhecida.

A maioria das preposições denota relações espaciais (e, analogamente, temporais) e são essas que serão foco de análise. Alguns exemplos de preposições [+Loc] são: em, entre, de, a, até, etc. Todas essas preposições exibem a relevância da posição de um tema em um espaço/tempo. Analogamente, para itens lexicais [-Loc], a relevância de posição ainda está presente, mas de forma diversa, pois 
assinala a noção de falta ou privação. Exemplos de preposições [-Loc] podem ser: sem, conforme, segundo, perante, etc.

No começo de sua elucidação acerca dos afixos [-Loc], Lieber aponta o caso dos privativos que, em inglês, tem como seu principal representante o sufixo -less, bastante produtivo em formar adjetivos denominais: loveless, hopeless, shoeless, etc. Como a semântica de -less é francamente privativa (loveless significa "sem amor" e shoeless, "sem sapatos"), parece fazer sentido caracterizar o esqueleto semântico desse sufixo não somente como [-dynamic], mas também como [-Loc].

Ao estudarmos especificamente os prefixos que apresentam a característica semântica em comum da negação, Lieber analisa os prefixos ingleses dis-, un-, in- e non-. No que diz respeito à semântica dos itens lexicais formados por esses prefixos, temos que $u n$-, in- $e$ dis- podem veicular uma variada gama de interpretações, tanto com leituras reversativas como com leituras contrárias (com possibilidade de gradação) e contraditórias (sem possibilidade de gradação): itens léxicos, tais como unhappy, inarticulate e discorteous, apresentam leituras contrárias; já unbreakable, infinite e disengaged apresentam, fazendo uso dos mesmos prefixos, leituras contraditórias. Ademais, os prefixos un- e dis-, pelo fato de também poderem se ligar a verbos, apresentam, além das leituras contrária e contraditória já mencionadas, a possibilidade da leitura reversativa, como em undress e disrobe (Lieber, 2004). Non-, diferentemente, parece ser o de semântica mais restrita, já que, ao não se ligar a verbos, não apresenta o significado de reversão. Ainda, non- parece ser estritamente negativo, apresentando apenas leituras contraditórias: smoker/non-smoker, human/nonhuman.

No que tange a questões de seleção léxica, Lieber aponta que o prefixo un- é de origem germânica e se liga, com frequência, também a palavras de mesma origem. Relativamente à seleção categorial, a autora ressalta que tanto un- quanto in- ocorrem principalmente com adjetivos e nomes, sendo que o primeiro parece ser mais produtivo que o segundo, especialmente em relação às formações neológicas. Além disso, un- é bastante produtivo em verbos com o sentido de reversão, assim como dis-. A autora aponta ainda que disse liga a adjetivos e a nomes, mas não apresenta, em inglês, um alto grau de produtividade. Para finalizar, nota-se que non- se faz produtivo em nomes e em adjetivos.

Tendo em vista esse quadro de múltiplos afixos negativos que apresentam significados relacionados, mas ainda assim variados, Lieber propõe que a polissemia desses afixos é o resultado da interação dos significados abstratos neles contidos com os significados de diferentes tipos de bases às quais eles podem se concatenar. Com isso em mente, a autora advoga por uma única característica na descrição semântica dos prefixos negativos, qual seja [-Loc]. 
O traço [Loc] é atribuído a itens lexicais para os quais posição ou lugar no tempo/espaço é relevante; consequentemente, em itens que não apresentarem esse traço, ou seja, itens [-Loc], a noção de posição ou espaço é irrelevante. Com efeito, Lieber assinala, [-Loc] sinaliza a noção de falta ou privação, principalmente na caracterização de determinados verbos, nomes e adjetivos que apresentam negação através de afixos derivacionais. [-Loc] é, então, na visão de Lieber, a única característica necessária para a descrição da prefixação negativa. Essa única representação dá origem a quatro nuances de significado levemente distintas, quais sejam: privação, negação contrária, negação contraditória e reversibilidade. A semântica e o tipo de base ao qual o prefixo vai se adjungir apresentam, pois, um papel fundamental, já que a semântica de cada afixo só poderá ser determinada quando este estiver em contato com sua base. Com isso em mente, algumas sistematizações em relação às leituras que emergem com diferentes tipos de bases podem ser feitas (Lieber 2004:125):

1. Para obtermos um significado reversativo em itens lexicais derivados, temos a presença de um prefixo negativo juntamente com um verbo que implica um resultado mutável.

2. Para obtermos um significado contrário em itens derivados, temos a concatenação de um prefixo de negação com uma base que apresenta uma interpretação graduável ou escalar.

3. Para obtermos um significado contraditório, precisamos da adjunção de um prefixo de negação a uma base que apresenta uma interpretação estritamente não escalar.

Lieber (2004) defende que não há necessidade de diferenciar entre os tipos de negação (privação, negação contrária, negação contraditória, reversão) em uma teoria de semântica lexical. A interpretação dos vários itens lexicais prefixados negativamente vai depender das propriedades do prefixo juntamente com a natureza semântica do item lexical e de esta poder ou não ser analisada como graduável. Esses afixos, então, podem ser considerados exemplos de uma polissemia construtiva.

Vejamos, a seguir, como esse traço se aplica aos dados do PB no estudo de Bona (2014).

\subsection{A análise de Bona (2014), com base na proposta de Lieber (2004)}

Em sua dissertação de mestrado, Bona analisa 1497 ocorrências de itens lexicais prefixados por des-, presentes no Dicionário de Usos do Português do Brasil (Borba 2002). Desse número, 538 são adjetivos, 488 são substantivos e 471 são verbos. Sem considerar estágios derivacionais anteriores, des- parece ser bastante produtivo com todas as classes gramaticais, não 
apresentando diferenças numéricas muito significativas entre uma e outra. Ao se considerar a explicitação de estágios derivacionais precedentes, parece que a postulação de uma seleção rígida para o prefixo des-, em que este só se adicione em estágios adjetivais e verbais, não condiz com os dados, tendo em vista que foram obtidas 488 ocorrências de substantivos prefixados por des- e, desse número, 52 são nomes primitivos ou denominais e 16 são nomes deadjetivais; os 420 restantes são deverbais. Com esse resultado acerca dos substantivos, em que apenas $16(3,2 \%)$ são nomes deadjetivais, a autora vê a impossibilidade de considerar as afirmações de Silva e Mioto (2009) no que diz respeito à seleção categorial do prefixo. Com o intuito de melhor respaldar esse argumento, foram analisados os estágios derivacionais precedentes também dos adjetivos:

- Dos 538 adjetivos do corpus, 437 são adjetivos deverbais (desacelerado, desanimador, desconectado), 72 são adjetivos primitivos, deadjetivais ou em último estágio de derivação (descontente, desleal, desfeliz) e 29 são adjetivos denominais (desarmônico, desgraçado, desonroso).

Considerando que $86 \%$ dos substantivos apresentam um estágio deverbal anterior e $81,2 \%$ dos adjetivos também, a autora defende que, ao analisar estágios precedentes de derivação, des- é produtivo apenas com verbos. Relativamente a des- em adjetivos, as afirmações de Silva e Mioto (2009), que já não procederiam em termos categóricos, também não encontram respaldo em termos de produtividade. A descrição semântica dos autores (a qual aponta que des- em adjetivos é negação e des- em verbos é reversão) também não é corroborada pelos dados, considerando que, em verbos estativos, a noção atualizada por des- pode também ser de simples negação.

De forma geral, sem considerar estágios derivacionais anteriores, analisando apenas as ocorrências registradas nas entradas no Dicionário de Usos do PB de Borba (2002), pode-se dizer que des- adjunge-se a adjetivos, substantivos e verbos. Averiguando-se os estágios derivacionais precedentes, constata-se que des- tende a se ligar mais a bases verbais.

Em termos semânticos, Lieber advoga por uma única característica na descrição dos prefixos negativos, qual seja [-Loc]. A definição da pesquisadora se aplica muito convenientemente aos adjetivos e à maioria dos substantivos prefixados por des-, licenciando paráfrases com a noção de "falta de" em nomes deadjetivais e em nomes derivados de verbos estativos. No entanto, alguns nomes deverbais provenientes de verbos de ação-processo (tais como descongelamento, desencarnação) parecem não se enquadrar tão facilmente nesse traço, haja vista a noção de inversão veiculada por esse prefixo quando adjungido a verbos de mudança, o que repercute nos nomes provindos deles. Nesses casos, [-Loc] parece não ser suficiente. 
Mesmo que Lieber defenda que [-Loc] seja a única característica necessária para a descrição da prefixação negativa, incluindo nessa representação a possibilidade de origem do significado de reversão, acreditamos que, sendo assim, seu traço apresenta um poder explanatório bastante amplo ao considerar que a semântica de cada afixo só poderá ser determinada quando este estiver em contato com sua base. Frente a isso, defendemos que a solução para melhor descrever verbos que apresentam a noção de reversão quando prefixados por des- está no próprio sistema de traços proposto por Lieber, qual seja a explicitação da presença do traço [+IEPS], responsável pela noção de trajetória. Entendemos que esse traço já se faz presente em todos os verbos que implicam processos de mudança e, ao adicionarmos o prefixo negativo, o traço [-Loc] atua sobre [+IEPS], não anulando a presença da trajetória, mas invertendo sua direção.

Lieber (2004) argumenta que [IEPS] nos permite distinguir um número significativo de classes verbais:

(8) Classes verbais e seus traços (Lieber 2004:30)

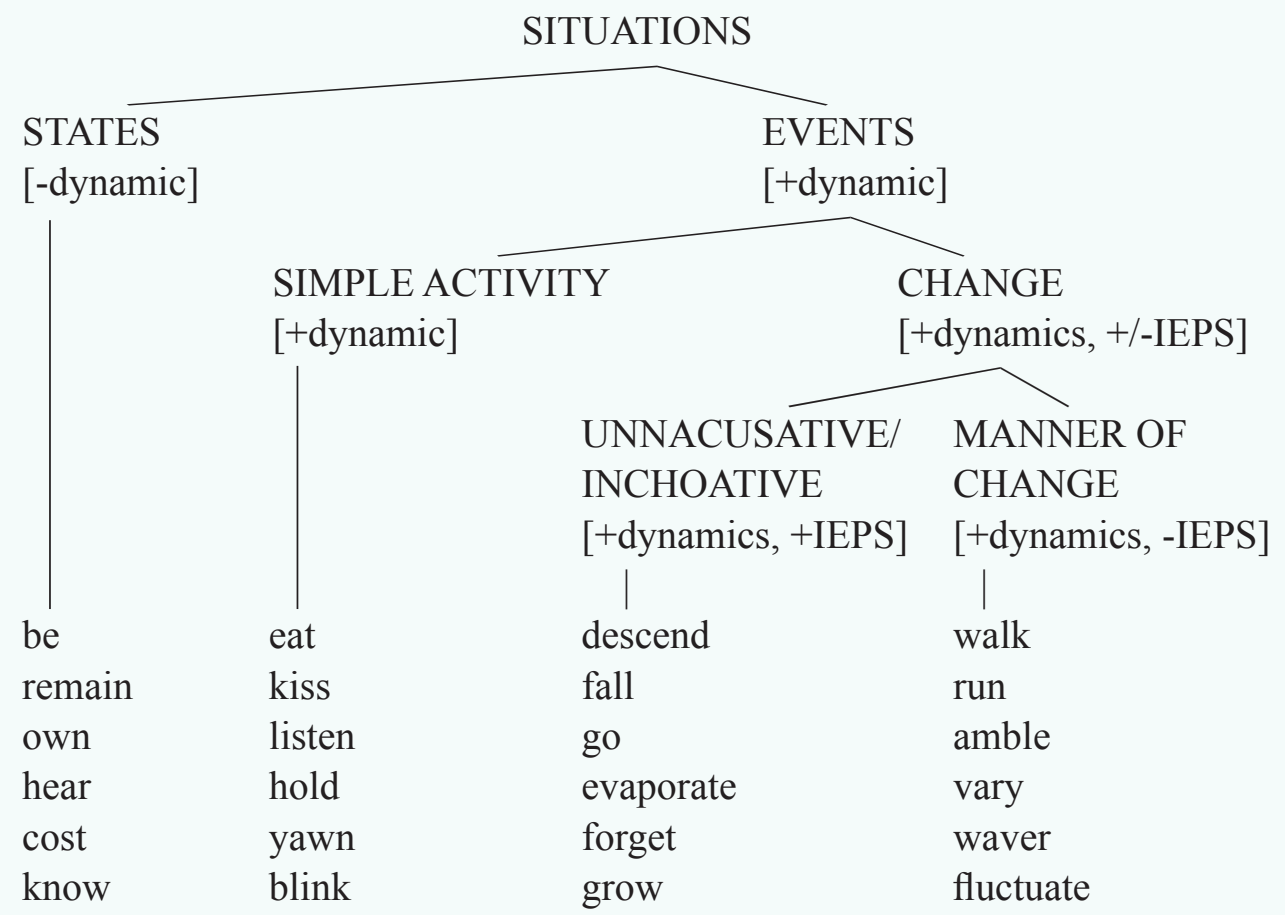

Com isso em vista, relativamente aos verbos, ele é adicionado ao traço [+dynamic] para distinguir uma subclasse de verbos que denotam movimento ou mudança em trajetórias direcionadas de uma classe que denota movimento ou mudança com uma trajetória ao acaso. A primeira classe é composta por verbos inacusativos/incoativos, tais como cair, ir, evaporar, esquecer, crescer, etc., e a segunda por verbos de modo de movimento, como caminhar, correr, flutuar, oscilar, etc. Verbos com o traço [IEPS] são aqueles em que alguma 
mudança de lugar ou estado acontece, seja essa mudança direcionada ([+IEPS]) ou casual ([-IEPS]). Verbos sem esse traço são verbos de atividades simples para os quais a noção de trajetória é irrelevante. Isso naturalmente explica a impossibilidade de adjunção de des- a verbos que denotam apenas o modo de mudança e não implicam nenhum tipo de deslocamento através de uma trajetória, tais como *descorrer, *despular ou *desflutuar. No entanto, ainda não esclarece a agramaticalidade de construções do tipo *descrescer. Com isso em vista, acredita-se que os itens lexicais individualmente fornecem a informação de "possibilidade de reversão da trajetória". Havendo essa possibilidade, o traço [-Loc] é o que será responsável por ela.

\section{Metodologia e análise de dados}

Neste trabalho, retomamos os dados de Bona (2014) para verificar a hipótese de que o prefixo des- tenha passado a denotar apenas a reversão de uma trajetória de mudança (aplicando-se produtivamente no estágio atual da língua a verbos de mudança ou a nomes deverbais), não mais se configurando como um prefixo de negação de estado. Para tanto, realizamos uma pesquisa diacrônica sobre a datação dos nomes não deverbais prefixados com des-, assim como dos verbos estativos prefixados com des-, que denotam um sentido de negação. $\mathrm{O}$ objetivo é mostrar que essas formações têm datação muito antiga no português, o que favorece nossa hipótese de que o prefixo des- com um sentido de negação já foi produtivo em estágios anteriores da língua, mas deixou de ser no estágio atual. De modo a buscar indícios em favor dessa hipótese, comparamos estas datações com a de neologismos apresentados na pesquisa de Santos (2016), que indicam a prevalência do sentido de reversão de uma trajetória em novas palavras formadas com des- no português.

\subsection{Substantivos prefixados com des- a partir de bases primitivas}

Conforme mostramos na seção 3.3, a maioria dos substantivos prefixados com des- presentes no corpus de Bona (2014) é deverbal (86\%), o que vai ao encontro de nossa hipótese de que o processo produtivo no português é aquele em que o prefixo seleciona bases que denotam uma noção de trajetória ([+IEPS], nos termos de Lieber 2004). O problema para esta hipótese encontra-se nos dados de substantivos prefixados com des- a partir de bases primitivas, os quais apresentam predominantemente uma semântica de negação. Para esses casos, a hipótese que defendemos é que sua entrada no léxico do português resulta de um período em que o prefixo des- com o sentido de negação era produtivo na língua. Na Tabela 1, apresentamos alguns dos principais substantivos com essas características presentes no corpus de Bona (2014), com a datação e o significado propostos pelo Dicionário Houaiss (2009) para essas formações: 
Tabela 1 - Datação e significado de substantivos prefixados com des- a partir de bases primitivas

\begin{tabular}{|l|l|l|}
\hline Substantivos & \multicolumn{1}{|c|}{ Datação } & \multicolumn{1}{c|}{ Significado } \\
\hline Desamor & s.XIII & $\begin{array}{l}\text { Perda ou ausência de amor; desafeição; } \\
\text { desprezo. }\end{array}$ \\
\hline Desarmonia & 1844 & $\begin{array}{l}\text { Oposição de interesses, de sentimentos; } \\
\text { divergência; discordância. }\end{array}$ \\
\hline Desatenção & $1639-1696$ & Ausência de atenção; distração. \\
\hline Descaso & $1817-1819$ & Desconsideração; desdém; desprezo. \\
\hline Desfavor & s. XV & $\begin{array}{l}\text { Perda do favor de que se desfruta junto a } \\
\text { alguém; desgraça. }\end{array}$ \\
\hline Desgraça & 1559 & $\begin{array}{l}\text { Perda das boas graças de que se desfruta } \\
\text { junto a alguém; desfavor; desvalimento. }\end{array}$ \\
\hline Desvalor & 1836 & Ausência ou perda de valor; depreciação. \\
\hline Desvantagem & 1836 & Falta de vantagem; prejuízo. \\
\hline Desvergonha & 1567 & Falta de vergonha; despudor. \\
\hline
\end{tabular}

Como podemos observar na Tabela 1, as primeiras ocorrências dessas formações registradas pelo Houaiss (2009) datam do período entre o século XIII e o início do século XIX. São formações, portanto, que fazem parte do léxico da língua há vários séculos, sendo que muitas delas parecem ter caído em desuso no estágio atual da língua, tais como desamor, desvalor e desvergonha. Na seção seguinte, mostramos que a situação dos adjetivos é bastante similar.

\subsection{Adjetivos prefixados com des- a partir de bases primitivas}

Assim como no caso dos substantivos, Bona (2014) constata que a maioria dos adjetivos prefixados com des- presentes em seu corpus são também deverbais $(81,2 \%)$. No entanto, há também casos de adjetivos prefixados com des- a partir de bases primitivas, os quais apresentam uma semântica de negação. A Tabela 2 mostra os principais casos exemplificados por Bona (2014), com a datação e o significado propostos pelo Dicionário Houaiss (2009): 
Tabela 2 - Datação e significado de adjetivos prefixados com des- a partir de bases primitivas

\begin{tabular}{|l|l|l|}
\hline \multicolumn{1}{|c|}{ Adjetivos } & \multicolumn{1}{c|}{ Datação } & \multicolumn{1}{c|}{ Significado } \\
\hline Desamigo & s. XIII & Não amigo; hostil. \\
\hline Descontente & s. XV & $\begin{array}{l}\text { Que não está contente; insatisfeito; } \\
\text { desgostoso. }\end{array}$ \\
\hline Deselegante & 1899 & $\begin{array}{l}\text { Que ou aquele que é desprovido de bom } \\
\text { gosto ou discrição; desalinhado. }\end{array}$ \\
\hline Desigual & s. XIII & Dessemelhante; diferente. \\
\hline Desleal & s. XIII & Que não é leal. \\
\hline
\end{tabular}

Os dados na Tabela 2 mostram que os adjetivos não deverbais prefixados com des- também datam de um período entre o século XIII e o século XIX, configurando-se como formações bastante antigas na língua. O significado das formas é o de negação, resultado da operação por meio do traço [-Loc], o qual simplesmente nega a semântica da base, o que acreditamos ter sido um processo de formação de palavras produtivo em estágios anteriores da língua.

Antes de apresentarmos os dados de neologismos com o prefixo des-, observemos ainda a datação de alguns verbos estativos prefixados com des-, os quais também apresentam semântica de negação, resultante do mesmo processo envolvido na formação dos adjetivos discutidos nesta seção.

\subsection{Verbos estativos prefixados com des-}

São muitos os verbos formados pelo prefixo des- em Bona (2014), totalizando 472 ocorrências. Na maioria dos casos, a semântica desses verbos é a de reversão de uma trajetória de mudança, como esperado na prefixação com des- com bases que são marcadas com o traço [+IEPS]. Entretanto, o corpus ainda apresenta alguns verbos estativos, com uma semântica de negação, como é o caso de desamar, desconhecer, descrer e deslembrar, por exemplo. Seguindo a análise que propomos neste artigo, defendemos que o traço [-Loc] é capaz de dar conta desses itens derivados, haja vista serem de semântica estativa: desamar é não amar, descrer é não crer e deslembrar é não ter lembrança, ou seja, des- opera através de [-Loc] no sentido de simplesmente negar a base.

Apesar de as definições de Borba contemplarem apenas uma noção estativa de negação nesses casos, des- parece ser um prefixo produtivo de semântica reversativa quando ligado a verbos em geral. Na maioria dos casos, ambas as interpretações (negação e reversão) são possíveis, e é provável que, em formações recentes, o sentido mais prototípico disparado por des- seja mesmo o de reversão. Dada sua polissemia, vemos que um estudo mais detalhado acerca do percurso histórico desse afixo em português se faz pertinente para que os efeitos da diacronia sejam mais bem explicitados e filtrados na formalização 
semântica. Se observarmos a datação oferecida por Houaiss (2009) para as primeiras ocorrências dessas formas no português, observamos que elas se encontram no léxico da língua desde o século XIII ou XV (na Tabela 3, o significado das formas é retirado de Borba 2002):

Tabela 3 - Datação e significado de verbos estativos prefixados com des-

\begin{tabular}{|l|l|l|}
\hline \multicolumn{1}{|c|}{ Verbos } & \multicolumn{1}{c|}{ Datação } & \multicolumn{1}{c|}{ Significado } \\
\hline Desamar & s. XIII & Não amar; malquerer. \\
\hline Desconhecer & s. XIII & Não conhecer; estranhar. \\
\hline Descrer & s. XIII & Não crer; desacreditar. \\
\hline Deslembrar & s. XV & Não ter lembrança; olvidar. \\
\hline
\end{tabular}

De forma a buscar indícios em favor da hipótese de que o prefixo des- com o sentido de negação não faz mais parte de uma regra de formação de palavras produtiva no português, realizaremos na seção seguinte uma análise contrastiva das formações neológicas com o prefixo des- em português, fundamentada nos dados apresentados por Santos (2016).

\subsection{Santos (2016): um olhar sobre os neologismos com o prefixo des-}

Santos (2016) apresenta dados sobre neologismos formados com o prefixo des- no PB, coletados no Observatório de Neologismos do Português Contemporâneo (TermNeo, USP). Em sua pesquisa, a autora analisa o prefixo considerando sua capacidade de atuar produtivamente, do ponto de vista sincrônico, na formação de novas palavras na língua. No que diz respeito às formações verbais, foram encontradas pela autora 48 formações, as quais poderiam ser classificadas como tendo uma semântica de reversão. ${ }^{1}$ Como não são formas dicionarizadas, apresentaremos as datações do corpus da autora para classificar a ocorrência dos neologismos, bem como os significados propostos por ela:

1. A autora faz a ressalva de que, dados alguns significados idiossincráticos de certos verbos, como desinventar e desfinanciar, a classificação deveria ser mais específica, pois são eventos não passíveis de reversão. 
Tabela 4 - Datação e significado de neologismos verbais com des-

\begin{tabular}{|l|l|l|}
\hline \multicolumn{1}{|c|}{ Verbos } & \multicolumn{1}{c|}{ Datação } & \multicolumn{1}{c|}{ Significado } \\
\hline Desinvadir & 1996 & Deixar vazio o lugar que foi invadido. \\
\hline Desacusar & 1996 & Deixar de acusar. \\
\hline Desvuduzar & 1996 & Reverter o processo de colocar um "vudu". \\
\hline Des-satanizar & 1994 & Desfazer a imagem negativa, satânica. \\
\hline Desintermediar & 2000 & Deixar de realizar a intermediação. \\
\hline Desincentivar & 2004 & Reverter o processo de incentivar \\
\hline
\end{tabular}

Os dados apresentados na Tabela 4 elucidam que os neologismos verbais prefixados com des-apresentam, majoritariamente, significado de reversão, que, segundo o quadro teórico adotado, consideramos como resultado da operação do traço [-Loc] em uma base que apresenta o traço [+IEPS], ou seja, [-Loc] reverte a trajetória do processo já presente na base verbal. Vejamos agora algumas das formações neológicas em substantivos prefixados por des- analisadas por Santos (2016). A autora aponta que, ao todo, foram encontrados 69 itens lexicais cujas bases são substantivas. Apresentamos algumas delas na tabela abaixo:

Tabela 5 - Datação e significado de neologismos de substantivos com des-

\begin{tabular}{|l|l|l|}
\hline \multicolumn{1}{|c|}{ Substantivos } & \multicolumn{1}{|c|}{ Datação } & \multicolumn{1}{c|}{ Significado } \\
\hline Dessocialização & 2000 & Reversão do processo de socializar. \\
\hline Des-hospitalização & 1997 & $\begin{array}{l}\text { Reversão do processo de hospitalizar. } \\
\text { Negação incide sobre o resultado do } \\
\text { processo. }\end{array}$ \\
\hline Desfavelização & 1996 & Reversão do processo de favelizar. \\
\hline Deslavagem & 1996 & $\begin{array}{l}\text { Reversão do processo de lavar. Valor } \\
\text { da base é figurado, relacionado à } \\
\text { lavagem cerebral, o que implicaria uma } \\
\text { transformação de crenças e atitudes. }\end{array}$ \\
\hline Desconversa & 1994 & Contrariar o que se falou anteriormente. \\
\hline
\end{tabular}

Santos (2016) relata que, na maior parte dos substantivos analisados, também se verificou o valor reversivo, considerando que muitas bases são nominalizações de verbos. Substantivos como desacontecimento (1996), desimportância (1994), desrelação (1998), que apresentam uma noção de negação simples segundo a autora, são formações esporádicas no corpus, decorrentes de algum efeito de estilo de seus autores, em que o prefixo também acresce um tom pejorativo ao item lexical.

Por fim, passemos ao estudo das formações neológicas em adjetivos: 
Tabela 6 - Datação e significado de neologismos adjetivais com des-

\begin{tabular}{|l|l|l|}
\hline \multicolumn{1}{|c|}{ Adjetivos } & \multicolumn{1}{c|}{ Datação } & \multicolumn{1}{c|}{ Significado } \\
\hline Desarmador & Sem registro & Que reverte a ação de armar. \\
\hline Desarquivador & Sem registro & Que reverte a ação de arquivar. \\
\hline Desenrustido & Sem registro & $\begin{array}{l}\text { Que reverte o resultado da ação } \\
\text { de enrustir. }\end{array}$ \\
\hline Desdivinizado & 1997 & $\begin{array}{l}\text { Que reverte o resultado da ação } \\
\text { de divinizar. }\end{array}$ \\
\hline
\end{tabular}

Mais uma vez, percebemos como o significado de reversão parece ser recorrente em formações neológicas, agora mais especificamente no que diz respeito aos adjetivos. Dos 48 itens lexicais analisados em seu trabalho, a maioria deles é participial, segundo a autora: despoliciado (1997), descomandado (1999), desalavancado (1997), desaldeado (1999). Sendo assim, a anteposição desse prefixo a uma base participial é capaz de privar o elemento derivado de características próprias a esses verbos. Ou seja, o significado de negação simples disparado por des- nessas palavras está relacionado à semântica estativa gerada por meio do adjetivo.

\section{Considerações finais}

Este trabalho teve por objetivo estudar os aspectos semânticos do prefixo des-. Nossa hipótese de que o significado de negação associado a esse prefixo não é mais produtivo no PB atual parece ter sido corroborada por meio da pesquisa diacrônica sobre a datação dos nomes não deverbais prefixados com des-, assim como dos verbos estativos prefixados com des-, que denotam um sentido de negação. Nosso objetivo foi mostrar que essas formações têm datação muito antiga no português.

Além disso, por meio da comparação dessas datações com as de neologismos apresentados na pesquisa de Santos (2016), parece haver indícios que apontam para a prevalência do sentido de reversão de uma trajetória em novas palavras formadas com des- no português. Testes experimentais com pseudopalavras estão em andamento para verificarmos, mais acuradamente, a produtividade, no PB de hoje, do prefixo des- com verbos, adjetivos e substantivos, juntamente com a semântica por ele atualizada.

Recebido em: 07/12/2016

Aprovado em: 07/07/2017

Emails:

Camila De Bona camidebona@gmail.com Pablo Nunes Ribeiro pablonribeiro@yahoo.com.br 


\section{Referências}

BORBA, Francisco da Silva. 2002. Dicionário de Usos do Português do Brasil, São Paulo: Editora Ática.

DE BONA, Camila. 2014. Os prefixos de negação des- e in- no PB: Considerações morfossemânticas. Dissertação (Mestrado em Letras), Instituto de Letras, UFRGS, Porto Alegre.

HOUAISS, Antônio. 2009. Dicionário Eletrônico Houaiss da Língua Portuguesa. Rio de Janeiro: Objetiva.

JACKENDOFF, Ray. 1983. Semantics and Cognition. Cambridge, MA: MIT Press.

JACKENDOFF, Ray. 1990. Semantic Structures. Cambridge, MA: MIT Press.

LEVIN, Beth. 1993. English Verb Classes and Alternations: A Preliminary Investigation. Chicago: University of Chicago Press.

LIEBER, Rochelle. 2004. Morphology and Lexical Semantics. Cambridge: Cambridge University Press.

MEDEIROS, Alessandro Boechat de. 2010. Para uma abordagem sintático-semântica do prefixo des-. Revista da ABRALIN, vol.9, n.2: 95-121.

RIBEIRO, Pablo Nunes. 2014. Revisitando a Semântica Conceitual de Jackendoff: um estudo sobre a semântica verbal no $P B$ sob a perspectiva da Hipótese Locacional. Tese (Doutorado em Letras), Instituto de Letras, UFRGS, Porto Alegre.

SANTOS, Alice Pereira. 2016. Morfologia em diacronia - os caminhos e desvios de um afixo na história da língua: o percurso histórico-semântico do prefixo des- em bases sufixadas e em formações parassintéticas. Tese (Doutorado em Filologia e Língua Portuguesa), Faculdade de Filosofia, Letras e Ciências Humanas, USP, São Paulo.

SILVA, Maria Cristina Figueiredo; MIOTO, Carlos. 2009. Considerações sobre a prefixação. ReVEL, v. 7, n. 12: 1-22. 